will constitute an irregularity, and may easily result in the formation of a satellite. And if a quasi-tide is raised in the nebula by the presence of a distant mass, the same result may be produced.

The suggestion contained here made no further appearance until it had blossomed into the formal 'tidal theory'. In a paper received by the Royal Astronomical Society on Nov. 3, 1916, and published in Mem. R.A.S., 62, part 1, 1917, Jeans considered "the motion of tidally distorted masses, with special reference to theories of cosmogony ".

In recent years [he wrote] the position of this hypothesis [Laplace's] has been challenged by speculations based ultimately upon the conception of tidal forces providing the required tendency to separation, the most complete and definite of these speculations being found in the Planetesimal Hypothesis of Chamberlin and Moulton. In the present paper I have attempted to follow up mathematically the changes in a mass of matter as the tidal forces acting on it continually increase.

As a result of the investigation the following conclusion was reached:

The genesis of our solar system can very probably be attributed to tidal action; the explanation leaves room for a good deal of uncertainty in matters of detail, but does not demand anything impossible or very improbable. The evidence we have been able to obtain suggests that a system generated by tidal action might quite well have characteristics, both qualitative and quantitative, such as are observed in our system. The origin which seems most probable is not that of the planetesimal hypothesis.

Further developments-showing, like the planetesimal hypothesis, some modification of the original conjectures - are recorded by Jeans in "Theories of Cosmogony and Stellar Dynamics " (1919), Supplement to Nature, March 1, 1924, and "Astronomy and Cosmogony" (2nd edition, 1929).

In Ast. Nach. 4308 (Jan. 1, 1909), T. J. J. See advanced the idea that the planets were not de- tached from the primitive sun but were " captured, or added from without, and have had their orbits reduced in size and rounded up under the secular action of the nebular resisting medium " formerly pervading our solar system. The idea was further developed in "Researches on the Evolution of the Stellar Systems ", vol. 2, p. 357, 1910.

Dr. Harold Jeffreys discussed the planetesimal hypothesis in a paper in Mon. Not. R.A.S., December 1916 ( $\%$, 84). He considered that it was open to the objection that the planetesimals would be fused and volatilised by collisions, and so could not build up the planets by the slow aggregation postulated by Chamberlin. In Science Progress (July 1917) he outlined some considerations on the early history of the solar system which were developed more fully in Mon. Not. R.A.S., "78, 424, April 1918. Starting, like Chamberlin, from geological data, he came to the opposite conclusion; namely, that the planets were formerly liquid or gaseous. Dismissing the nebular hypothesis of their origin by an argument described as " a modification of that of Jeans", he turned his attention to the tidal theory.

This theory [says Jeffreys] forms part of the Planetesimal Hypothesis of Chamberlin and Moulton; its dynamical possibility has been proved by Jeans; and I have shown here and elsewhere [in Science Progress] that the system it would lead to would resemble our own in several striking features. It will be definitely adopted as a postulate in the present paper.

Jeffreys's further work is summarised in his book "The Earth" (2nd edition, 1929). The only subsequent development of significance here is the substitution (in Mon. Not. R.A.S., 89, 636, 731; 1929) of an actual collision for a close approach between the sun and the visiting star.

We end, therefore, where we began; the latest, like the earliest, known theory attributes our existence to the impact of another cosmic body on the primitive sun.

Herbert Dingle.

\title{
The History of Ergot
}

$\mathrm{E}$ RGOT has been under active scientific investigation for two generations, and has provided sociological problems for ten centuries; its secrets are now almost all laid bare, and at the moment when investigators are likely to turn aside from its study to that of other subjects, Prof. Barger has come forward to write its biography.* Usually a subject of so much interest attracts the notice of the mere collator ; fortunately, ergot has not done so, and it has been left for the story to be written by a distinguished chemist, who may be congratulated on having sufficient imagination to realise how rich a story it could be. Few even of those who have worked on ergot would have guessed it.

The main importance of ergot in the past was not medicinal but as a cause of epidemic disease; instead of a healing draught, it was a scourge.

* Ergot and Ergotism: a Monograph based on the Dohme Lectures delivered in Johns Hopkins University, Baltimore. By Prof. George Barger. Pp. xvi $+279+6$ plates. (London and Edinburgh: Gurney and Jackson, 1931.) 15s. net.

$$
\text { No. } 3253 \text {, VoL. 129] }
$$

Strange as it may seem to us in Great Britain, "rye is still the chief cereal in a large belt of Europe extending from Holland across Northern Germany, Czecho-Slovakia, Austria, Poland, and Central Russia", and in Poland, for example, four times more rye is eaten than wheat. From the ergot present in the rye have come the many epidemics of ergotism.

Ergotism occurs in two forms, known respectively as gangrenous and convulsive; in the first form the symptoms are due to the effect of ergot on the blood vessels, as a result of which the blood supply to the extremities is cut off, so that gangrene occurs and the limb drops off; loss of the leg below the knee is common. Convulsive ergotism, on the other hand, is not an affection of the blood vessels, but of the central nervous system; it is characterised by the appearance of areas of degeneration in the spinal cord, and the symptoms are convulsive seizures. 
The distribution of the two forms of ergotism has long been a mystery, which Prof. Barger has now solved by the light of the recent work of $\mathrm{E}$. Mellanby in Sheffield. For example, about 1770 there was an epidemic of gangrenous ergotism in Sologne on the left bank of the Rhine, while in Hanover on the right bank there was an epidemic of convulsive ergotism. Why should there have been so sharp a difference in the symptoms in the two localities? Now Mellanby has shown that convulsive ergotism is readily produced in dogs which are given one or two grams of ergot daily, provided that the diet is free from vitamin $A$; but the same amount of ergot produces no harmful effect if vitamin $A$ is added to the diet. Prof. Barger points out that the difference in the 1770 epidemics in Sologne and Hanover fits in admirably with this work ; Sologne was a dairy-farming district where the inhabitants had milk and butter ; the vitamin A present in the diet prevented the appearance of nervous symptoms. In Hanover, on the other hand, the soil was very poor and unable to support cattle, so that the peasants had little save rye to eat; in consequence the nervous type of ergotism appeared.

Records of gangrenous ergotism go back to A.D. 857, when the "Annales Xantenses" state that a great plague of swollen blisters consumed the people by a loathsome rot, so that their limbs were loosened and fell off before death. The early approach of the disease is marked by a feeling of intense heat in the part affected, and this was responsible for the name 'holy fire', which during the twelfth century became associated with St. Anthony, when many sufferers began to visit the saint's relics preserved in an abbey near Vienne in Dauphiné. There was a hospital attached to the abbey, and the sick either died within seven days of their arrival or were ' miraculously' restored to health by the wholesome food they received there. The historical details which Prof. Barger has collected make fascinating reading of a kind which is only too rare in modern scientific monographs; we learn how ergotism even prevented a military campaign in Russia in 1723 .

The history of the introduction of ergot into medicine is also surprising; the earliest mention of its use as a drug is in the 1582 edition of Adam
Lonicer's "Kreuterbuch", but its real entry into official medicine took place in the United States! "In the Medical Repository of New York there appeared in 1808 an "Account of the Pulvis parturiens, a Remedy for quickening Child birth ', in the form of a letter from Dr. John Stearns of Saratoga county to Mr. S. Akerly." The method of administration was either in decoction or in powder. "It expedites lingering parturition and saves to the accoucheur a considerable portion of time."

Prof. Barger's monograph includes also botanical, chemical, pharmacological and clinical, pharmaceutical, and forensic sections. While Tanret in 1875 was the first to isolate one of the ergot alkaloids in crystalline form, this substance, ergotinine, is inactive, and Prof. Barger himself, together with Dr. F. H. Carr, was responsible in 1906 for the isolation of ergotoxine, which is almost certainly the more important of the two active alkaloids. All four alkaloids, ergotinine, ergotoxine, ergotamine, and ergotaminine, have recently been obtained in crystalline form by $\mathrm{S}$. Smith and G. M. Timmis, and are known to be separate chemical individuals. Ergotinine has the formula $\mathrm{C}_{35} \mathrm{H}_{39} \mathrm{O}_{5} \mathrm{H}_{5}$, while ergotamine and ergotaminine are isomers having the formula $\mathrm{C}_{33} \mathrm{H}_{35} \mathrm{O}_{5} \mathrm{~N}_{5}$. Only the formula of ergotoxine remains in doubt, the probability being that it is also isomeric with ergotamine. There remains the puzzle of the occurrence of ergotamine, the active alkaloid isolated by Stoll; for no other worker has obtained ergotamine from ergot of rye, the claims of Forst to have done so being open to doubt. Smith and Timmis readily obtained ergotamine from the ergot of Festuca elatior, but failed to do so from any of the many samples of ergot of rye which they examined. Stoll's statement that ergotamine is present in ergot of rye is, therefore, lacking in confirmation.

Prof. Barger's book, in its completeness and in the care taken in its presentation, is a work of art; it is a model which should inspire others, particularly those interested in pharmaceutical science, to attempt to do the same for other drugs. One imagines that among the pharmacists the book has created a sensation, which will provide them with eager discussion for some months to come.

\section{Obituary}

\section{Prof. E. Wrison}

$\mathrm{T}$ EE sudden death on Feb. 17 of Prof. Ernest Wilson, emeritus professor of electrical engineering and fellow of King's College, London, came as a shock to his many friends and caused a widespread feeling of loss in scientific and engineering circles. Though frail in appearance, he possessed a vitality which was the envy of his numerous friends, together with an engaging personality and a derotion to duty exhibiting the utmost selflessness, which endeared him to students and all with whom he came in contact.

Born in Lincolnshire, on Nov. 25, 1863, he joined the works of Messrs. Greenwood and Batley,
Leeds, where he served his time as a six-o'clock lad, learning some of life's lessons, as well as laying a solid foundation for his life's work. It is interesting to note that while at this works he was engaged on the construction of the first Brush machine and the first Ferranti alternator made in England.

Malking the most of his opportunities and attending technical classes at the Yorkshire College, Wilson secured a Whitworth scholarship, which enabled him to proceed to Germany, 1886-87, and take up further studies and gain engineering experience. During his study of electro-technology in Germany, he assisted Prof. Kohlrauseh

No. 3253, Vou. 129] 